\title{
A ludicidade aplicada à Educaçáo Física: a prática nas escolas
}

\section{The playfulness Applied to Physical Education: the practice in schools}

\author{
Cláudio Delunardo Severino ${ }^{1}$ \\ Renato Porrozzi ${ }^{2}$
}

\begin{abstract}
Resumo
O presente artigo aborda a importância das atividades lúdicas no processo ensino-aprendizagem relacionado à prática da Educação Física, em âmbito escolar. O trabalho realizado baseou-se no aspecto da ludicidade, utilizando os conteúdos pré-estabelecidos pelo Plano de Componente Curricular, unindo a característica que toda criança apresenta em gostar de brincar. Discute-se como as atividades lúdicas tornam-se fundamentais dentro desse processo, pois proporcionam o prazer às crianças, além de contribuírem para o seu desenvolvimento físico, intelectual e social. As atividades lúdicas representam um importantíssimo papel tanto no universo como no interesse da criança, devendo por isso serem utilizadas como um importante instrumento de ensino. Através da brincadeira, a criança tem a possibilidade de se relacionar consigo e com o meio, além de ter, a partir do seu conhecimento acerca do brincar, um contato mais prazeroso com os fundamentos específicos das modalidades esportivas que são desenvolvidas nas aulas de Educação Física.
\end{abstract}

Palavras-chave: Atividade Lúdica, Educação Física Escolar.

\section{Abstract}

The present study approaches the importance of the ludic activities inside of the process teaching-learning related to the practice of the Physical education in school extent, appearing that the work based on the aspect of the ludicity can present the contents preestablished by the Plan of Curricular Component taking advantage the deep knowledge of the children in knowing how to play. The ludic activities become fundamental inside of that process, because provide the pleasure to the children, besides they contribute to your physical development, intellectual and social. The ludic activities represent a very important paper in the universe and in the child's interest, owing for that be interpreted and used as an important teaching instrument. Through the ludicity, the child has the possibility to relate with itself and with the enviroment, and taking their playing knowledge, a more pleasent contact with the specific foundations of the sporting modalities that they are developing in the classes of Physical Education.

Keywords: Ludic activities. School Physical Education.

${ }^{1}$ Mestre em Ensino em Ciências da Saúde e do Meio Ambiente - Centro Universitário de Volta Redonda - UniFOA. ${ }^{2}$ Docente do Programa de Mestrado Profissional em ciência da Saúde e do Meio Ambiente - UniFOA 


\section{INTRODUÇÃO}

É cada vez maior a necessidade do homem em se apropriar de conhecimentos, os quais, por consequência de uma globalização que parece não medir esforços para quebrar todos os paradigmas relacionados ao limite, são disponibilizados numa velocidade que ultrapassa a barreira do que outrora era imaginável. Tal necessidade é o que alimenta a sua avidez em desenvolver a sua capacidade crítica, além de torná-lo um ser em permanente exercício de sua cidadania.

Durante toda a sua complexa existência, o homem busca o conhecimento e o discernimento através de diversas experiências, no contato com o desconhecido, na relação consigo e também com o meio onde vive. No caso da criança, essa busca traduz-se na expressão da ludicidade, dos jogos simbólicos. Invariavelmente, praticamente tudo o que é relacionado ao seu universo apresenta uma ligação ao seu saber brincar. Consideramos que devido a tal característica, a criança constrói, através das brincadeiras, um caminho no qual consegue satisfazer suas necessidades de aprendizagem e desenvolvimento.

A ludicidade, representada pelo ato de brincar, é um importante e imprescindível instrumento pedagógico. A brincadeira viabiliza a participaçáo dos alunos quando em contato com os conteúdos sugeridos por um Plano de Componente Curricular, tornando assim o processo de ensino-aprendizagem uma prática prazerosa, enfatizando a espontaneidade, a alegria e a socialização. Os jogos e brincadeiras propiciam a ampliação dos conhecimentos infantis, por meio da atividade lúdica.

No âmbito escolar, especificamente em relação à Educação Física, torna-se imprescindível a inserção de momentos lúdicos durante as aulas, procurando, a partir desses, uma maior possibilidade de êxito no que diz respeito a atingir os objetivos propostos.

Neste artigo, abordaremos a importância da ludicidade no processo ensino-aprendizagem relacionado à prática da Educação Física, apontando que o trabalho nela baseado pode apresentar os conteúdos pré-estabelecidos pelo Plano de Componente Curricular, aproveitando o que a criança tem de melhor, ou seja, o conhecimento do saber brincar. Com uma revisão bibliográfica do tema, temos o objetivo discutir com diversos autores e, juntamente com nossa prática diária em escolas, exploraremos as possibilidades da ludicidade relacionada ao processo ensino-aprendizagem na prática esportiva.

No que diz respeito ao âmbito escolar, a atividade lúdica deve, sempre que possível, estar presente em todas as disciplinas, por ser um valioso instrumento pedagógico. Ela auxilia a aprendizagem através da alegria, da espontaneidade e da liberdade que a criança apresenta ao se relacionar com aquilo que ela reconhece. No entanto, a atividade físi- ca nos apresenta como um campo fértil para que a criança possa estabelecer um diálogo entre o brincar e a construção do seu esquema corporal, formando assim uma consciência de seu corpo como meio de comunicação e socialização.

\section{ENTRE O BRINCAR E O APRENDER}

A ludicidade ou o simples ato de brincar faz parte do cotidiano da criança, desde o seu nascimento. Ao brincar, a criança passa a desenvolver não somente a sua inteligência, mas também o seu esquema corporal e a sua socialização. Apesar disso, no contexto atual, devido à urbanização, propagação de jogos eletrônicos e acesso à tecnologia, ela já não convive com a prática da brincadeira da mesma maneira como ocorria algum tempo atrás. Hoje, as crianças não possuem o mesmo privilégio que as de anos atrás, que conviviam constantemente com brincadeiras que lhes proporcionavam uma enorme vivência (SILVA JUNIOR, 2005).

No decorrer do desenvolvimento de sua experiência de vida, a criança, conscientemente ou não, vai aos poucos se integrando na sociedade à sua maneira, já que a representação do universo infantil é distinta em relação ao do adulto. De acordo com Celante (in VENÂNCIO; FREIRE, 2005) tal distinção ocorre porque a criança, além de possuir uma diferente estrutura cognitiva, ainda náo se submeteu aos processos de ajustamento social. A atividade lúdica, além de proporcionar prazer e diversão, representa em algumas ocasiôes um momento de provocação do pensamento da criança e também de sua inserção social. Neste caso, cabe não somente à Educaçáo Física, que trabalha diretamente com o corpo e o movimento, mas também a todas as disciplinas, compreender as particularidades do universo infantil.

A criança sempre apresentou como característica a ludicidade, considerando que a mesma é indispensável à saúde do indivíduo. $\mathrm{O}$ ato de brincar representa a aprendizagem de uma maneira lúdica. Para Venâncio e Costa (2005), no brincar, o indivíduo está tentando compreender e controlar o mundo, compreender e interpretar a si mesmo.

Apesar de que na maioria dos casos ocorra a predominância do prazer, há situações em que o desprazer caracteriza a atividade lúdica. Vygotsky (apud KISHIMOTO, 2008) afirma que nem sempre o prazer é apresentado como uma característica, pois em certos momentos há esforço e desprazer na busca do objetivo da brincadeira.

A partir de tais enfoques, nota-se o quanto a atividade lúdica está presente no universo infantil. Portanto, podemos afirmar que, além do prazer e da descontração, os jogos e brincadeiras tornam-se importantes instrumentos pedagógicos pelo fato de fazerem parte do próprio processo de desenvolvimento da criança. 
Winnicott (1975) afirma que é exatamente no brincar que tanto as crianças como os adultos são capazes de expressar a sua liberdade de criação. Para o autor, a atividade lúdica é sempre uma experiência criativa, uma experiência na continuidade espaço-tempo, uma forma básica de viver.

Para resumir as características formais da atividade lúdica ou o jogo propriamente dito, recorremos ao conceito de Huizinga (2007, p. 16, grifo do autor):

Poderíamos considerá-lo uma atividade livre, conscientemente tomada como "não-séria" e exterior à vida habitual, mas ao mesmo tempo capaz de absorver o jogador de maneira intensa e total. É uma atividade desligada de todo e qualquer interesse material, com o qual não se pode obter qualquer lucro, praticada dentro de limites espaciais e temporais próprios, segundo uma certa ordem e certas regras. Promove a formação de grupos sociais com tendência a rodearem-se de segredo e a sublinharem sua diferença em relação ao resto do mundo por meio de disfarces ou outros meios semelhantes.

Quanto à formação de grupos sociais citada, podemos afirmar que através do contato com atividades lúdicas, as crianças desenvolvem a sensibilidade e a desenvoltura para a socialização, além da capacidade de raciocínio. Além disso, na prática de atividades lúdicas são incentivadas outras potencialidades que muito auxiliam o desenvolvimento motor, além de uma melhora da saúde e da qualidade de vida. Acerca desta questão, Winnicott (1975) ressalta que, ao brincar, a criança também tem a possibilidade de ser conduzida a relacionamentos grupais, já que a atividade lúdica pode ser uma forma de comunicação.

Observamos a importância que o emprego de jogos, que se enfatiza o divertimento, dentro do processo de ensino-aprendizagem, onde o trabalho envolvendo os objetivos propostos previamente pelo Plano de Componente Curricular pode ser trabalhado através da ludicidade, facilitando o desenvolvimento pleno da criança.

Vários autores abordam a necessidade que a criança tem de possuir momentos em sua vida em que as atividades lúdicas possam ter um espaço privilegiado. Atualmente, torna-se notório o fato de que um número considerável de atividades extras limita o tempo da criança que seria destinado à brincadeira. Para tornar o quadro ainda mais preocupante, aos poucos a criança vai trocando o pouco tempo que lhe resta para se dedicar às brincadeiras pelo contato com o aparelho de televisão que causando vários malefícios tanto em relação a saúde física, quanto ao desenvolvimento social.

Outros autores vão ainda mais longe, como Almeida (2003, p. 36, grifo do autor) que sugere:
Como se não bastassem os desencontros na família e o desrespeito na escola, a criança é vítima da televisão. Esta representa uma grande indústria de venda associada ao capital monopolista, e a vítima mais cobiçada é a criança. Por meio de desenhos, filmes, comerciais, novelas, programas infantis, incutem-lhe, desde cedo, valores de consumo, submissão, sonhos, ilusóes, preparando-a para ser a "cidadâ" de amanhã.

A criança, em benefício de seu próprio desenvolvimento, necessita de oportunidades que lhe despertem a imaginação e a descoberta de seu corpo. Para tal, os adultos que a cercam devem ter tal consciência diante do importante papel que cumprem. Pais, professores e familiares são fundamentais para que a criança tenha o mínimo de acesso às brincadeiras. Para Silva Junior (2005), há a necessidade de haver educação do movimento, consciência do corpo, e deve-se pensar, agir, criar, imaginar e... brincar.

\subsection{Uma visão do brincar na perspectiva de Jean Piaget}

Acerca dessa forma de atividade, Piaget (1978) aborda, no contexto do pensamento infantil, diferenciando seis critérios utilizados frequentemente:

- $\quad$ O jogo encontra sua finalidade em si mesmo;

- O jogo é uma atividade espontânea, diferente da atividade voltada para o trabalho;

- O jogo é uma atividade que proporciona prazer ao participante. Neste caso, o prazer representa a adaptaçáo afetiva do indivíduo ao real;

- $\quad$ O jogo apresenta uma significativa falta de organização;

- $\quad$ jogo estabelece um comportamento livre em relaçáo ao conflito;

- $\quad$ O jogo é uma atividade que apresenta uma motivação intensa.

Segundo Friedmann (2006), para que haja a possibilidade de compreensão da concepção de Piaget acerca da brincadeira (jogo), torna-se necessário esclarecer os conceitos de assimilação e acomodação, pois eles se fazem presentes em todas as fases do desenvolvimento.

A acomodação é o processo pelo qual a criança modifica seu estágio mental em resposta a agentes externos. Já a assimilação é o processo pelo qual a criança incorpora elementos externos ao seu próprio esquema (FRIEDMANN, 2006). Em diversas ocasiōes, um se destaca em relação ao outro. Outras vezes, eles se apresentam em equilíbrio.

Sendo assim, Piaget (1978, p. 217) define a brincadeira como: 
[...] a expressão de uma das fases dessa diferenciação progressiva: é o produto da assimilaçấo, dissociando-se da acomodação antes de se reintegrar nas formas de equilíbrio permanente que dele farão seu complemento, ao nível do pensamento operatório ou racional.

Ao estabelecer conceitos acerca da brincadeira, Piaget (1978) distingue três tipos de estrutura em diferentes fases de desenvolvimento: o exercício, o símbolo e a regra.

Percebe-se que no período até dois anos, as atividades desenvolvidas referem-se, basicamente, ao exercício. É fácil observar uma criança, neste período, brincando com o simples movimento de uma bola, sempre de maneira repetitiva, a fim de atentar para os efeitos e resultados (PIAGET, 1978).

$\mathrm{Na}$ fase seguinte, até os seis anos, as atividades lúdicas se mostram de maneira simbólica. Aos poucos, há uma preocupação evidente na sequência das histórias que são criadas como se tentassem se aproximar da realidade (PIAGET,1978).

Por fim, surge a fase onde a criança, dos sete anos em diante, ultrapassa a fantasia para situações reais através dos jogos de construção que representam um tipo de transição entre o jogo simbólico e o jogo de regras (PIAGET, 1978).

Para Anderáos (in MOREIRA, 2006), Piaget, em suas observaçóes, pôde destacar que as crianças ao longo de seu desenvolvimento passam por quatro estágios, no que se refere ao modo como lidam com as regras do jogo:

[...] crianças bem pequenas, até mais ou menos três anos, jogam em função do seu próprio desejo, divertem-se sozinhas, fazem gestos repetitivos e regulares ao brincar, mas esse brincar é totalmente individual e nada tem a ver com o jogo em si: é o estágio das regras motoras e não sociais ou individuais; crianças entre três e seis anos parecem jogar como os grandes; imitam-nos fazendo muitas das coisas que aqueles fazem ao jogar. No entanto, olhando de perto, veremos que essas crianças mudam as regras a bel prazer toda vez que for interessante para elas! Piaget chamou esse estágio de egocêntrico: cada criança joga por si, embora todos estejam imitando os mais velhos. Essas crianças não se dão ao trabalho de combinar como vão jogar, não codificam as regras; elas saem jogando e pronto! Entre sete e dez anos, aproximadamente, as crianças passam a usar, de fato, as regras entre si para organizarem como jogar. As regras fornecem um meio de controle mútuo entre elas; é o estágio da cooperação nascente; como último estágio, após os onze anos, as crianças passam a codificar as regras antes do jogo. Às vezes o tempo gasto combinando como jogar, com que regras, é maior do que aquele do próprio jogo. As partidas são regulamentadas em minúcias e todos os casos possíveis de acontecer são discutidos para se construírem regras adequadas. As crianças passam a ter interesse pelas regras em si, buscando construí-las, as mais justas e completas (MENIN, 1996, p. 43-44 apud ANDERÁOS, 2006 in MOREIRA, 2006).
Considerando as afirmações da citação anterior, podemos perceber que os estágios são: simples práticas individuais e regulares; imitação dos maiores com egocentrismo; cooperação e interesse pela regra em si mesma (ANDERÁOS, 2006 in MOREIRA, 2006).

No que tange à compreensão que as crianças têm sobre as regras dos jogos, Piaget pôde afirmar, a partir de suas observaçóes, que as crianças de até três anos não têm um entendimento das regras. Já entre três e oito, encaram as regras como algo imutável. Transgredi-las é algo muito errado. No último estágio da compreensão das mesmas, surge a consciência, quando percebem as regras como uma construçáo coletiva e que podem ser alteradas quando houver consenso do grupo (PIAGET, 1978).

Assim, constata-se que no jogo pode-se observar a evolução do juízo moral da criança, correspondendo aos estágios de desenvolvimento cognitivo de Piaget.

\subsection{Uma visão da brincadeira na perspectiva de Lev Vygotsky}

Segundo Vygotsky (1998), é através da análise do social que se compreende como o indivíduo adquire o conhecimento.

Desta forma, a relação entre o meio social e cultural, além do papel que a criança desempenha neste contexto contribuem, decisivamente, na formação das funçôes psicológicas. Assim, a ação e os modos sociais de utilizar os objetos são aprendidos na interação prática, que futuramente provoca, também, a necessidade de dominar o mundo dos objetos humanos, provocando o surgimento das primeiras brincadeiras (VYGOTSKY, 1998).

Para Vygotsky, na brincadeira, a criança estabelece uma situação imaginária identificada como o próprio ato de brincar. $\mathrm{O}$ autor ainda aponta que toda atividade lúdica pressupóe regras, mesmo aquelas que são colocadas pelas relaçóes imaginárias (VYGOTSKY; LURIA; LEONTIEV, 1988).

Os mesmos autores (1988) definem que a brincadeira é caracterizada por uma estrutura em que o motivo se encontra no próprio processo. $\mathrm{O}$ motivo pelo qual a brincadeira tenha importância na vida de uma criança deve-se ao fato da ampliação do universo vivido pela mesma. Tal ampliação consiste no aumento do número de objetos que constituem um desafio no sentido de que a criança possa dominá-los. Trata-se da existência de um obstáculo a ser ultrapassado, na medida em que o desenvolvimento (da criança) lhe possibilita a tal.

Ainda segundo Vygostsky, Luria e Leontiev (1988), a criança apresenta como característica o querer agir em relaçáo aos objetos para poder exercer domínio sobre eles, apesar de nem sempre possuir as ferramentas necessárias para isso. Diante disso, para minimizar a distância entre o "querer" e o "conseguir", a criança faz uso da ludicidade, que 
não é considerada uma atividade produtiva e o seu objetivo não está no resultado, mas na própria ação.

Vygotsky (1998) aponta que a partir da faixa etária que vai dos três aos seis anos ocorre a possibilidade de divergência entre a visão e o significado da ação.

Vygotsky (1998, p.127) ainda aponta que:

A raiz das restriçóes situacionais sobre uma criança situa-se no aspecto principal da consciência característica da primeira infância: a união de motivaçôes e percepçâo. Nesta idade, a percepção não é, em geral, um aspecto independente, mas, ao contrário, é um aspecto integrado de uma reação motora. Toda percepçáo é um estímulo para a atividade.

Dessa forma, fica clara a afirmaçáo de Vygotsky quanto ao fato de que na atividade lúdica, a criança aprende a agir numa esfera cognitiva e não apenas numa esfera visual externa. Vygotsky (1998) ainda considera que o jogo contém todas as tendências do desenvolvimento sob forma condensada, sendo, ele mesmo, uma grande fonte de desenvolvimento.

Para que se compreenda a importância da brincadeira no desenvolvimento psíquico da criança, Vygotsky entende que se faz um entendimento acerca do papel do jogo, bem como as suas regras.

Vygostsky, Luria e Leontiev (1988, p. 122) afirmam que a brincadeira é considerada como atividade principal na vida da criança:

Chamamos atividade principal àquela em conexão com a qual ocorrem as mais importantes mudanças no desenvolvimento psíquico das crianças e dentro da qual se desenvolvem processos psíquicos que preparam o caminho de transiçáo da criança para um novo e mais elevado nível de desenvolvimento.

Vygotsky (1998) aponta que a criança se desenvolve através de brincadeiras, pois as mesmas oportunizam a criação de uma zona de desenvolvimento proximal ${ }^{3}$.

Podemos afirmar que nas atividades lúdicas das crianças, as condiçóes reais podem ser substituídas por outras, porém, a sequência das açóes náo chega a ser alterada, devendo ela corresponder à realidade identificada pela criança. Isto posto, podemos citar as regras como sendo atributos característicos da atividade (VYGOTSKY; LURIA; LEONTIEV, 1988).

Vale ressaltar que os autores enfatizam que o jogo das crianças não nasce de uma situação imaginária, mas de uma real. Trata-se da impossibilidade de realização de uma ação que, devido a isso, procura na imaginação uma solução efêmera.
Na brincadeira, o que a criança realiza é sempre próximo do que consideramos como real. A partir desse entendimento, quando a criança consegue compreender o universo que a cerca, passa a ter condiçóes de contribuir para a sua melhoria.

$\mathrm{Na}$ ação da criança, nota-se que ela consegue generalizar as atitudes. Dessa forma, ao brincar, a criança capta os traços mais característicos de pessoas de sua convivência, transferindo-os para a situação vivida (VYGOTSKY; LURIA; LEONTIEV, 1988).

Para Vygotsky (2001), a brincadeira é o meio natural para que a criança possa desenvolver comportamentos morais. É na atividade lúdica que a criança encontra uma considerável quantidade de normas, que não foram estabelecidas por adultos.

A criança se subordina às regras do jogo não porque esteja ameaçada de punição ou tema algum insucesso ou perda, mas apenas porque a observância da regra lhe promete satisfação interior com a brincadeira, uma vez que a criança age como parte de um mecanismo comum constituído pelo grupo que brinca. A náo observância da regra náo ameaça com nenhuma outra coisa a não ser o fato de que a brincadeira venha a fracassar, perca o seu interesse e isso representa um fator regulador bastante forte do comportamento da criança (VYGOTSKY, 2001, p. 315).

As idéias de Vygotsky acerca da ludicidade ampliam, de certa forma, a visão piagetiana. Para Vygotsky, o jogo é essencialmente "desejo satisfeito" que se origina de "desejos insatisfeitos" que se tornam afetos da criança (FRIEDMANN, 2006).

Para Vygotsky (1988), a brincadeira apresenta como característica o envolvimento de uma situação imaginária criada pela própria criança, ou seja, segundo o autor, o brincar da criança é a imaginação transformada em ação.

Segundo Friedmann (2006), outra característica da brincadeira enfatizada por Vygotsky é quanto às regras das mesmas. Neste particular, Vygotsky afirma que não existe atividade lúdica sem regras. A situação imaginária do jogo já apresenta regras de comportamento, não necessitando que as mesmas sejam explicitadas.

A partir das consideraçóes de autores de grande relevância, podemos considerar que a brincadeira contribui para o desenvolvimento moral da criança, partindo da premissa de que a mesma deve estar sempre almejando um equilíbrio entre o meio em que vive e o seu próprio comportamento.

${ }^{3}$ É a distância entre o nível de desenvolvimento real, que se costuma determinar através da solução independente de problemas e o nível de desenvolvimento potencial, determinado através da solução de problemas sob a orientação de um adulto, ou em colaboraçáo com companheiros mais capazes. 


\section{O PAPEL DO PROFESSOR}

Relacionar-se com o próximo é um comportamento fundamental para que se alcancem os objetivos propostos no campo profissional e, porque não dizer, também no contexto pessoal. Diante disto, a relação entre o professor e o aluno merece uma cuidadosa análise, já que a mesma está condicionada aos interesses e objetivos de ambas as partes, além de ser o principal caminho para o êxito do processo de ensino-aprendizagem. Dentro deste quadro, a relação estabelecida entre ambos está diretamente amparada nos conteúdos, na organização dos trabalhos e nas ações pedagógicas realizadas nas aulas.

Um dos objetivos do professor deve ser proporcionar momentos em que os alunos, além de assimilar os conteúdos apresentados, descubram como executar com prazer as atividades propostas. Todavia, é bastante questionável o quanto os professores, em especial os de Educação Física, promovem situaçóes que alcancem tal propósito.

Segundo Ronca e Terzi (2005), uma considerável quantidade de professores pensa que a sua atribuição dentro da escola é apenas passar o conteúdo inserido no seu Plano de Componente Curricular Desta fora, o conhecimento é apenas transmitido, sem oportunidade nem tempo para poder ser criado, discutido e interpretado.

$\mathrm{O}$ ato de ensinar não se limita apenas a transmitir informaçôes e conteúdos (RONCA; TERZI, 2005). Ensinar deve estar ligado ao ato de educar, a contribuir para a formação da criança e despertar nela a consciência crítica. Ensinar também é oportunizar às crianças um maior juízo de valores, uma visão de mundo mais ampla e o pleno hábito de exercício da cidadania.

O papel tanto da escola como do próprio professor vai além da mera transmissão de conteúdos. Ele se ampara no diálogo, no cumprimento de sua missão social. Alarcão (2001, p. 26) aponta:

É a escola que se assume como instituição educativa que sabe o que quer e para onde vai. Na observação cuidadosa da realidade social, descobre os melhores caminhos para desempenhar a missão que lhe cabe na sociedade. Aberta à comunidade exterior, dialoga com ela. Atenta à comunidade interior, envolve todos na construçáo do clima de escola, na definiçấo e na realização do seu projeto, na avaliação da sua qualidade educativa.

Diante de tal afirmação, percebe-se que o professor comprometido com o valor da aprendizagem náo pode contentar-se com a educação bancária, ou seja, não deve se limitar apenas à transmissáo de conteúdos para que os mesmos possam ser assimilados e arquivados pelos alunos
(FREIRE, 2008). Deve, também, despertar no aluno a consciência crítica e um maior discernimento acerca das questôes sociais.

$\mathrm{Na}$ Educação Física, o professor tem um importante papel na edificação do novo, pois ele deve propiciar a vivência lúdica como expressão real de um trabalho comprometido com a construção de uma nova escola (GARIGLIO apud ASSIS, 2005). É o professor que, através da proposição de brincadeiras e jogos, promove a intervenção a favor da construçáo do conhecimento. $\mathrm{O}$ professor, no papel de interventor, tem a oportunidade de propiciar a aprendizagem que atende as necessidades criativas e sociais da criança. Para tal, é necessária uma relação docentediscente que possibilite açóes que permitam à criança o auto-conhecimento.

O professor de Educação Física, na qualidade de promotor do processo ensino-aprendizagem, ao inserir jogos e brincadeiras em suas aulas, deve ser capaz de interpretálos e encontrar neles qualidades pedagógicas pertinentes, as quais devem adequar-se a sua metodologia e seus princípios (SCAGLIA in VENÂNCIO; FREIRE, 2005; RIZZI, HAYDT, 2007).

Para que a criança tenha a motivação necessária para desenvolver as atividades propostas em aula, torna-se primordial que o professor diversifique as suas açóes pedagógicas, objetivando sempre um ambiente leve e descontraído. Assim, oportunizará a aprendizagem, além de promover uma maior interação entre a escola, o professor e a criança.

\section{O CASO DA EDUCAÇÃO FÍSICA}

Atualmente a Educação Física é vista como um dos pilares essenciais da formação do homem como um todo e, de acordo com o artigo 26, parágrafo $3^{\circ}$ da LDB 9394/96, deve estar presente em toda a escolaridade fundamental. Todavia, nem todas as instituiçóes educacionais reconhecem a sua importância. Diante desse quadro, a prática da Educação Física acaba muitas vezes colocada em segundo plano, sendo considerada apenas como um momento em que os alunos "jogam bola", não se reconhecendo o verdadeiro valor que existe em relação ao mesmo.

Na perspectiva de Darido (2004), torna-se imprescindível a consideração de que conteúdos que proporcionem a valorização de conceitos, valores e atitudes, todos no mesmo nível de importância. Isto se baseia no fato de que a prática da Educação Física nas escolas possui uma amplitude maior do que o mero ensino-aprendizagem de modalidades esportivas. Tal processo necessitará de ações em que a criança ou o adolescente, ao vivenciá-lo, possa identificar o objetivo ou a finalidade do que está sendo executado. 
No decorrer das aulas, a atividade lúdica possibilita à criança momentos para criar e representar a realidade e as experiências por ela vivenciadas no seu cotidiano. O Referencial Curricular Nacional para a Educação Infantil (BRASIL, 1998) enfatiza a importância das brincadeiras dentro do processo de construção do conhecimento.

Nas brincadeiras, as crianças transformam os conhecimentos que já possuíam anteriormente em conceitos gerais com os quais brinca. Por exemplo, para assumir um determinado papel numa brincadeira, a criança deve conhecer alguma de suas características. Seus conhecimentos provêm da imitação de alguém ou de algo conhecido, de uma experiência vivida na família ou em outros ambientas, do relato de um colega ou de um adulto, de cenas assistidas na televisão, no cinema ou narradas em livros etc. A fonte de seus conhecimentos é múltipla, mas encontram-se ainda, fragmentados. É no ato de brincar que a criança estabelece os diferentes vínculos entre características do papel assumido, suas competências e as relaçóes que possuem com outros papéis, tomando consciência disto e generalizando para outras situaçōes. (BRASIL, 1998, p. 27)

Tal observação enfatiza com propriedade as contribuiçôes da atividade lúdica em relação ao desenvolvimento pleno da criança. Associada à aplicação dos conteúdos propostos pelo Plano Curricular de Educação Física, as brincadeiras condicionadas à atuação do docente podem também contribuir para a aprendizagem de conteúdos relacionados a outras disciplinas.

Santos (1997) comenta que a ludicidade é uma necessidade do ser humano, pois o seu desenvolvimento facilita a aprendizagem, o desenvolvimento sócio-cultural, colabora para uma boa saúde mental, facilita os processos de socialização, comunicação, expressão e construção de conhecimento.

Pode-se constatar novamente que as atividades lúdicas possuem grande importância, sendo assim, um campo obrigatório para o desenvolvimento afetivo, cognitivo e motor do ser humano.

Reconhecendo que a Educação Física é uma prática pedagógica, ela assume o papel de resgatar os valores que possam privilegiar o coletivo sobre o individual, garantir a solidariedade e o respeito humano levando à compreensão de que a brincadeira se faz com o outro e não contra o outro (ASSIS, 2005). Diante de tal afirmação, percebe-se que a atividade lúdica se transforma em uma possibilidade a mais em prol do desenvolvimento global da criança e do adolescente.

Paternost (in VENÂNCIO; FREIRE, 2005) entende que as aulas de Educação Física cumprem o seu papel quando trazem para os educadores o real significado da interdependência entre ação, vivência e compreensão a jovens que estão buscando estruturar-se diante de um contexto social. Sendo assim, utilizar-se das atividades lúdicas nas aulas de Educação Física será resgatar as inúmeras possibilidades trazidas ao se fazer representar, através da linguagem corporal, vivências e representaçóes que contribuirão para a socialização da criança.

A ludicidade é uma necessidade do ser humano em qualquer idade e não pode ser vista apenas como diversão. A promoção de atividades lúdicas, sejam elas individuais ou grupais, oportuniza situações privilegiadas que conduzem à aprendizagem e ao desenvolvimento pessoal, social e cultural, produzindo conhecimentos e experiências que se incorporarão à vida do aluno, abrindo-lhe possibilidades de ser livre e de tomar decisóes de acordo com a sua própria consciência (FREIRE, 2005).

\section{CONCLUSÁO}

Reflexôes sobre a utilização de atividades lúdicas nas aulas de Educação Física apontam a sua importância no processo de ensino-aprendizagem, a partir do entendimento de que as mesmas são de grande relevância para o desenvolvimento do indivíduo.

Entendemos ser atribuição do professor de Educação Física, através de suas práticas pedagógicas, oportunizar aos seus alunos inúmeras situaçóes para que possam vivenciar a ludicidade como prática de ensino, partindo do pressuposto de que ela é um rico instrumento para o crescimento da criança como um ser plural e apto para o exercício da cidadania. A partir do ato de brincar, o indivíduo coloca em prática a sua capacidade de atenção, estabelece um campo de possibilidades, exercita a sua imaginação, desenvolve habilidades motoras e se torna um ser autônomo, além de aprimorar a sua relação consigo e com o meio.

Fundamentamos aqui a importância que a atividade lúdica representa no que diz respeito à construção do conhecimento por parte da criança, reforçando a relevância da Educação Física dentro do contexto pedagógico. É a partir da prática da Educação Física baseada no lúdico, que se podem alcançar os objetivos de desenvolvimento do esquema corporal do aluno, associado a uma educaçáo de qualidade que pode ser conquistada através do que a criança tem de melhor, ou seja, o talento para brincar.

Ao brincar num determinado momento da aula, não se procura unicamente atingir algum objetivo estabelecido pelo Plano de Componente Curricular, mas também oportunizar ao aluno, através de açóes pedagógicas, a condição para que ele expresse, assimile e construa a sua própria identidade. 


\section{BIBLIOGRAFIA}

ALARCÃO, Isabel. Escola reflexiva e nova racionalidade. Porto Alegre, RS: Artmed, 2001.

ALMEIDA, Paulo Nunes de. Educaçáo lúdica: técnicas e jogos pedagógicos. 11 ed. São Paulo, SP: Loyola, 2003.

ASSIS, Sávio. Reinventando e esporte: possibilidades da prática pedagógica. 2 ed. Campinas, SP: Autores Associados, 2005.

BRASIL. Secretaria de Educação Fundamental. Parâmetros curriculares nacionais: Educação Física/Secretaria de Educação Fundamental. Brasília, DF: MEC/SEF, 1997.

DARIDO, Suraya Cristina; SOUZA JUNIOR, Osmar Moreira de. Para ensinar educaçáo física: possibilidades de intervenção na escola. Campinas, SP: Papirus, 2007.

FREIRE, Paulo. Pedagogia do oprimido. 47 ed. São Paulo, SP: Paz e Terra, 2008.

FRIEDMANN, Adriana. O desenvolvimento da criança através do brincar. São Paulo: Moderna, 2006.

HUIZINGA, Johan. Homo Ludens. 5 ed. São Paulo, SP: Perspectiva, 2007.

KISHIMOTO, Tizuko Morchida (Org.). Jogo, brinquedo, brincadeira e a educaçáo. 11 ed. São Paulo, SP: Cortez, 2008.

MOREIRA, Evando Carlos (Org.). Educação física escolar: propostas e desafios II. Jundiaí: Fontoura, 2006.

PIAGET, Jean. O julgamento moral da criança. São Paulo: Mestre Jou, 1977.

A formação do símbolo na criança: imitação, jogo e sonho, imagem e representação. Rio de Janeiro: Zahar, 1978.

RIZZI, Leonor; HAYDT, Regina Célia. Atividades lúdicas na educação da criança. 7 ed. São Paulo, SP: Ática, 2007.

RONCA, Paulo Afonso Caruso; TERZI, Cleide do Amaral. A prova operatória: contribuiçóes da psicologia do desenvolvimento. 30. ed. rev e amp. São Paulo, SP: Edesplan, 2005.
SANTOS, Santa Marli Pires dos. O lúdico na formaçáo do educador. Petrópolis, RJ: Vozes, 1997.

SILVA JUNIOR, Afonso Gomes da. Aprendizagem por meio da ludicidade. Rio de Janeiro, RJ: Sprint, 2005.

VENÂNCIO, Silvana; FREIRE, João Batista. O jogo dentro e fora da escola. Campinas, SP: Autores Associados, 2005.

VYGOTSKY, Lev; LURIA, Alexander; LEONTIEV, Alexei. Linguagem, desenvolvimento e aprendizagem. São Paulo: Ícone, 1988.

VYGOTSKY, Lev. A formaçáo social da mente: o desenvolvimento dos processos psicológicos superiores. 6 ed. São Paulo: Martins Fontes, 1998.

Psicologia pedagógica. São Paulo: Martins Fontes, 2001.

WINNICOTT, Donald. W. O brincar e a realidade, Rio de Janeiro, RJ: Imago, 1975.
Endereço para Correspondência:

Cláudio Delunardo Severino claudiodelunardo@gmail.com

Centro Universitário de Volta Redonda Campus Três Poços Av. Paulo Erlei Alves Abrantes, no 1325 , Três Poços - Volta Redonda / RJ CEP: $27240-560$ 